IV. - GENETICS

\title{
The animal breeding act of 1966 : 20 years of pig improvement in France
}

\author{
L. OLLIVIER *, J.P. RUNAVOT **, J. DAGORN **, R. GUEBLEZ**, \\ J. JEHANNO ***, R. KERISIT **, C. LEGAULT *, M. MOLENAT *, \\ P. SELLIER * \\ * I.N.R.A., Station de Génétique Quantitative et Appliquée, 78350 Jouy-en-Josas \\ ** I.T.P., B.P. 3, 35650 Le Rheu \\ *** C.E.M.A.G.R.E.F., Groupement de Rennes, B.P. 1312, 35016 Rennes Cedex
}

The Animal Breeding Act of 1966 and the ensuing creation of a National Board for Genetic Improvement in the Ministry of Agriculture made it possible rationally implement a national programme for genetic improvement of pig in France. This paper gives an account of its incidence on pig improvement over the last 20 years. The various regulations issued, the evolution of structures and means of genetic improvement, as well as the results obtained are successively presented. The breeding structure is organized according to a 3-levei "pyramid», namely selection nucleus-multiplication-production, whose evolution has been characterized by an increase in the size of the nucleus (more than doubled in terms of breeding sows), by the creation of breeding schemes under the control of various economic groups (26 schemes presently), by the development of crossbreeding (percentage of crossbred sows, negligible 20 years ago, now exceeds 70 p. 100 of the French production herd) and by a low impact of artificial insemination in production herds (below 3 p. 100 since 1970). Owing to the financial support of the Ministry of Agriculture and the Meat Commission, performance recording for production (farm and station performance testing, station progenytesting) and reproduction (on farm litter recording) traits have considerably developed since the late sixties. Phenotypic trends in production traits, in stations as well as in the field, generally agree with genetic gains estimated by various methods. The most noticeable gain is for lean tissue percentage in the carcass, which, in the Large White breed, has been increased by 12 points over 20 years. In addition, French sows now wean about 6 piglets more per year than 20 years ago, as a consequence of improved husbandry (earlier weaning) and of an increase in the use of crossbred sows. In conclusion, a tentative evaluation of the French system is presented, emphasizing the strengths and weaknesses of the system and the need to consider its future evolution. However, in spite of its deficiencies, such as a non-optimal use of the selection tools made available, an excessive number of low-size breeding groups and a lack of financial support from the industry as a whole, the organization set up in France following the Animal Breeding Act of 1966 has been largely beneficial to the pig industry. More than to the Act itself, the credit for such benefits is to be given to the state of mind it has created and which should be preserved for the future. 